\title{
COMPETITIVIDADE DA FRUTICULTURA BRASILEIRA NO MERCADO INTERNACIONAL
}

\author{
Rosemeiry Melo Carvalho ${ }^{1}$ \\ Miguel Henrique da Cunha Filho ${ }^{2}$
}

\begin{abstract}
Resumo - Esse artigo utiliza o indicador de vantagem comparativa revelada, a taxa de cobertura e o indicador de desempenho para analisar a competitividade das exportações brasileiras de frutas no mercado internacional, no período de 1990 a 2003. Os resultados obtidos mostram que a castanha de caju, a manga e o melão representam os "pontos fortes" desse setor. Porém, entre estes, apenas a manga e o melão estão em situação ótima de competitividade. Outros produtos de grande importância, como a laranja e a banana, estão em "situação de retirada", com desvantagem comparativa e perda de participação nos principais mercados de destinos. Em relação ao desempenho, a fruticultura brasileira tem ampliado seu espaço no mercado internacional, especialmente nos Países Baixos e no Reino Unido.
\end{abstract}

Palavras-chave: competitividade, vantagem comparativa, frutas brasileiras.

\section{Introdução}

Nos últimos anos, a crescente demanda de frutas in natura tem impulsionado o aumento da produção e das exportações dos principais países produtores, dentre os quais, a China, a Índia e o Brasil.

De acordo com dados da Food and Agriculture Organization of the United Nations (FAO) e do Ministério do Desenvolvimento, Indústria e Comércio Exterior (MDIC), nos anos de 1990 a 2003, o comércio mundial de frutas cresceu aproximadamente $70 \%$, enquanto as vendas externas

\footnotetext{
Doutora em Economia. Professora do Departamento de Economia Agrícola. Universidade Federal do Ceará (UFC).Email: melo@ufc.br

2 Doctorando en Planificación Territorial y Desarrollo Regional. Universidad de Barcelona,(UB) - España Professor do Departamento de Economia Universidade do Estado do Rio Grande do Norte (UERN). E-mail: mhcfilho@yahoo.com.br
} 
brasileiras desse produto aumentaram mais de $117 \%$. Porém, apesar de ser o terceiro maior produtor de frutas secas do mundo, as frutas brasileiras representam apenas $2 \%$ do mercado internacional do setor, ocupando o $20^{\circ}$ lugar entre os exportadores, o que indica a necessidade de uma inserção mais dinâmica e duradoura capaz de aumentar a competitividade internacional desse setor. Para isso, o Brasil está investindo em programas de sanidade, modernização da produção e marketing (Agroanalysis, 2005).

Tendo em vista a importância das vendas externas de frutas para a geração de divisas, emprego e renda no Brasil, o Ministério da Agricultura, Pecuária e Abastecimento (MAPA) tem empenhado esforços para elevar a competitividade e promover as exportações de frutas. Uma das principais ações desenvolvidas foi a criação do Programa de Desenvolvimento da Fruticultura (PROFRUTA), baseado no sistema de Produção Integrado de Frutas (PIF) ${ }^{3}$, já utilizado em muitos países, cujo principal objetivo é elevar o padrão de qualidade dos produtos aos patamares requeridos pelo mercado internacional (Kosoki e Andrigueto, 2003).

Nesse sentido, o objetivo geral deste estudo é analisar a evolução da competitividade da fruticultura brasileira no mercado internacional, no período de 1990 a 2003. Especificamente, pretende-se avaliar o desempenho das exportações e identificar os produtos que constituem "pontos fortes" nesse setor.

Além desta introdução, esse artigo traz mais três seções. A seguir, detalhase a metodologia utilizada para identificar os "pontos fortes" e o desempenho da fruticultura brasileira no mercado internacional. Nas duas últimas seções, são discutidos os resultados e apresentadas as principais conclusões.

\footnotetext{
O sistema PIF consiste numa orientação integrada e de livre adesão por parte de produtores e empacotadores, constituindo uma ferramenta importante para concorrer nos mercados nacional e internacional, e tem como pilares a base produtiva, a sustentabilidade, o monitoramento e a informação. No Brasil, esse sistema foi adotado desde o início de 1998, com a cultura macieira. A comercialização desse produto com o selo PIF foi iniciada em março de 2003, destinando-se a dez estados brasileiros e três países da UE.
} 


\section{Método de análise}

\subsection{Indicadores de competitividade}

Neste estudo, a performance externa da fruticultura brasileira foi analisada com base no conceito de competitividade revelada, utilizando indicadores relativos e absolutos, tais como indicador de vantagem comparativa revelada, taxa de cobertura e indicador de desempenho.

A construção desses indicadores é de grande importância para formular estratégias competitivas e fundamentar as decisões de caráter privado e políticas governamentais que visem melhorar a participação da fruticultura brasileira no cenário internacional (Silva et. al., 2001; Haguenauer, 1989). Desse modo, na próxima seção apresentam-se, detalhadamente, a fórmula de cálculo e a interpretação dos indicadores anteriormente propostos.

Para analisar as vantagens comparativas reveladas ${ }^{4}$ foi utilizado o indicador proposto por Balassa $(1965)^{5}$, calculado por:

$\operatorname{VCR}_{j}^{t}=\left(X_{j}^{t} / X^{t}{ }_{j w}\right) /\left(X^{t} / X^{t}{ }_{w}\right)$

em que $V C R^{t}{ }_{j}$ é indicador de Vantagem Comparativa Revelada da $j$ ésima fruta brasileira, no t-ésimo período; $X^{t}{ }_{j}$, valor das exportações brasileiras da j-ésima fruta; $X^{t}$, valor total das exportações brasileiras de frutas; $X^{t}{ }_{j w}$, valor das exportações mundiais da j-ésima fruta; $X^{t}{ }_{w}$, valor total das exportações mundiais de frutas; $j=1, \ldots .7$, principais frutas; $t=1, \ldots .14$, períodos de tempo.

\footnotetext{
4 Esse índice pressupõe que o comércio "revele" vantagens comparativas, uma vez que seu cálculo está baseado em dados depois de verificada a sua ocorrência.

5 Em virtude das distorções protecionistas que afetam as importações, o indicador VCR é calculado com base exclusivamente no valor das exportações.
} 
Se $V C R_{j}>1$, significa que o Brasil apresentará vantagem comparativa nas exportações de frutas, caso contrário, desvantagem comparativa revelada. Porém, deve-se ressaltar que esse indicador reflete a capacidade competitiva em dado momento (análise estática), e não permite capturar eventuais mudanças que venham a ocorrer no grau de competitividade setorial do País (análise dinâmica).

Para complementar a análise do índice de VCR será calculada a Taxa de Cobertura (TC), a qual pode ser obtida por:

$$
T C^{t}{ }_{j}=\frac{X^{t}{ }_{j}}{M^{t}{ }_{j}}
$$

em que $T C_{j}$ é taxa de cobertura da j-ésima fruta, no t-ésimo período; e $M^{t}{ }_{j}$, valor das importações brasileiras da j-ésima.

De acordo com Hidalgo (1998), os produtos que apresentarem, simultaneamente, VCR $>1$ e TC $>1$ constituem os "pontos fortes" do setor, enquanto os produtos que mostrarem, simultaneamente, desvantagem comparativa revelada e taxas de coberturas menores do que a unidade serão considerados "pontos fracos".

A evolução do comércio, em cada mercado de destino, pode ser analisada com base no indicador de desempenho (DES), calculado por:

$$
D E S^{t}{ }_{j}=X_{j z}^{t}-\left(X_{j z}^{t 0} * \frac{M_{j z}^{t}}{M_{j z}^{t 0}}\right),
$$


em que $D E S_{j}{ }^{t}$ é indicador de desempenho da j-ésima fruta brasileira, no t-ésimo período; $X_{j z}^{t}$, valor das exportações brasileiras da j-ésima fruta no ano (t), para o z-ésimo país; $X_{j z}^{t 0}$, valor das exportações brasileiras da j-ésima fruta no ano $\left(\mathrm{t}_{\mathrm{o}}\right)$, para o z-ésimo país; $M_{j z}^{t}$, importações totais da j-ésima fruta realizadas pelo z-ésimo país, no ano $t$; $M_{j z}^{t 0}$, importações totais da j-ésima fruta realizadas pelo z-ésimo país, no ano $t_{0} ; z=1, \ldots . n$, principais países de destino das frutas.

Para o cálculo do indicador de desempenho tomou-se como referência o ano de $1990^{6}$. Valores positivos mostram que o Brasil aumentou sua participação no mercado importador em relação ao período inicial, enquanto valores negativos indicam perdas de participação.

A partir da análise conjunta dos valores médios dos indicadores VCR e DES, os produtos podem ser classificados em quatro categorias: "situação ótima", se VCR $>1$ e DES $>0$; "situação de retirada", quando VCR $<1$ e DES $<0$;" situação de oportunidades perdidas", se VCR $<1$ e DES $>0$; "situação de vulnerabilidade", se VCR $>1$ e DES $<0$.

Com base nos valores e na evolução dos três indicadores anteriormente propostos, são apresentados e discutidos, a seguir, os principais resultados obtidos.

6 Nos casos em que não houve exportação nesse período, tomou-se como referência o ano imediatamente posterior. 


\subsection{Fonte dos dados e definição da amostra}

Para avaliar o desempenho das exportações e identificar os produtos que constituem "pontos fortes" da fruticultura brasileira, foram calculados o indicador de vantagem comparativa revelada (VCR), a taxa de cobertura (TC) e o indicador de desempenho (DES), bem como seus valores médios e taxas médias anuais de crescimento ${ }^{7}$ (TAC).

Os dados utilizados referem-se aos valores FOB (Free on Board), expressos em dólares americanos (US\$), no período de 1990 a 2003. As informações referentes ao comércio mundial de frutas foram obtidas da FAO.

Para o Brasil, o valor e o volume das exportações e importações, bem como a identificação dos principais mercados de destinos e de origem, foram obtidos do banco de dados do Sistema de Análise das Informações de Comércio Exterior (Sistema Aliceweb), da Secretaria de Comércio Exterior (SECEX), órgão vinculado ao MDIC.

No cálculo dos indicadores foram consideradas as sete principais frutas da pauta de exportação brasileira, quais sejam, castanha de caju ${ }^{8}$, manga, melão, laranja, maçã, banana e uva, as quais representam, em média, $87,09 \%$ das exportações do setor de frutas e $82,96 \%$ das exportações do grupo "frutas, cascas de cítricos e de melões". Além da representatividade, a utilização dessa amostra de produtos é justificada pelas dificuldades de compatibilizar os dados agregados da fruticultura mundial com a Nomenclatura Comum do Mercosul (NCM).

Calculadas com base na média aritmética.

8 Essa fruta é classificada de acordo com a Nomenclatura Comum do Mercosul (NCM), no capítulo referente à frutas frescas ou secas. 


\section{Resultados e discussão}

$\mathrm{Na}$ análise dos resultados foram identificados, inicialmente, os produtos considerados "pontos fortes" do setor de fruticultura. Posteriormente, analisou-se o desempenho dos produtos nos principais países de destino, classificando as frutas de acordo com sua situação competitiva.

\section{1. "Pontos fortes" e "pontos fracos" da fruticultura brasileira}

Os valores médios do indicador VCR indicam que castanha de caju, manga e melão apresentam vantagem comparativa, enquanto laranja, banana, maçã e uva, desvantagem. Em relação à taxa de cobertura, apenas a maçã e a uva apresentaram desvantagens, ou seja, o valor das importações brasileiras dessas frutas superou o das exportações (Tabelas 1 e 2).

Os produtos que apresentaram maiores vantagens comparativas foram a castanha de caju e a manga. Em 1990, a vantagem comparativa da castanha de caju era de 21,23, aproximadamente sete vezes maior que a da manga. No final do período, as VCR das duas frutas apresentaram aproximadamente o mesmo valor, pois ocorreu redução de $61,37 \%$ na VCR da castanha de caju e aumento de $98,95 \%$ da manga.

Desse modo, verifica-se que os produtos com sólidas oportunidades de inserção comercial, VCR $>1$ e TC $>1$, considerados "pontos fortes" na pauta de exportações de frutas brasileiras, foram a castanha de caju, a manga e o melão, enquanto os pontos fracos, $\mathrm{VCR}<1$ e TC $<1$, maçã e uva.

Os elevados valores das taxas de cobertura verificados para castanha de caju, manga e banana, em alguns anos, deveram-se, particularmente, ao reduzido valor das importações ocorridas nesses períodos. 
Porém, para que se possa melhor fundamentar as decisões sobre os investimentos no setor foi necessário analisar o desempenho do comércio de cada produto nos principais mercados de destino, a partir dos valores do indicador de desempenho (DES) de cada fruta.

Tabela 1- Brasil: vantagem comparativa revelada (VCR) das principais frutas brasileiras no mercado internacional, 1990 a 2003

\begin{tabular}{lccccccc}
\hline Ano & $\begin{array}{c}\text { Castanha } \\
\text { de caju }\end{array}$ & Manga & Melão & Laranja & Banana & Maçã & Uva \\
\hline 1990 & 21,23 & 2,91 & 2,19 & 1,04 & 0,33 & 0,13 & 0,14 \\
1991 & 18,47 & 2,46 & 3,06 & 1,14 & 0,55 & 0,07 & 0,36 \\
1992 & 18,29 & 2,54 & 2,57 & 0,71 & 0,39 & 0,63 & 0,36 \\
1993 & 13,47 & 5,59 & 4,60 & 0,88 & 0,33 & 0,42 & 0,65 \\
1994 & 10,87 & 5,78 & 4,91 & 1,27 & 0,24 & 0,54 & 0,40 \\
1995 & 17,14 & 7,27 & 2,52 & 1,26 & 0,08 & 0,20 & 0,49 \\
1996 & 17,98 & 7,56 & 3,93 & 0,83 & 0,10 & 0,05 & 0,28 \\
1997 & 14,75 & 4,96 & 2,73 & 1,01 & 0,17 & 0,35 & 0,19 \\
1998 & 12,71 & 7,71 & 3,51 & 0,63 & 0,16 & 0,19 & 0,24 \\
1999 & 8,29 & 6,60 & 3,14 & 0,89 & 0,21 & 0,90 & 0,29 \\
2000 & 8,98 & 6,04 & 2,50 & 0,58 & 0,19 & 0,88 & 0,38 \\
2001 & 8,53 & 8,81 & 4,19 & 1,07 & 0,28 & 0,54 & 0,62 \\
2002 & 7,35 & 9,68 & 4,13 & 0,29 & 0,58 & 0,81 & 0,93 \\
2003 & 8,20 & 8,38 & 4,29 & 0,35 & 0,40 & 0,71 & 1,22 \\
\hline Média & 13,20 & 6,16 & 3,45 & 0,85 & 0,29 & 0,46 & 0,47 \\
TAC & $-4,81$ & 13,95 & 11,83 & 1,94 & 12,38 & 120,38 & 28,31 \\
\hline Fonte: Elab & & & & & & &
\end{tabular}

Fonte: Elaborada pelos autores a partir de dados da SECEX/MDIC e da FAO.

${ }^{1 /}$ Taxa Média Anual de Crescimento. 
Tabela 2 - Brasil: taxa de cobertura (TC) das principais frutas, 1990 a 2003

\begin{tabular}{lccccccc}
\hline \multicolumn{1}{c}{ Castanha } & Manga & Melão & Laranja & Banana & Maçã & Uva \\
\hline 1990 & de caju & - & 0,00 & $480.289,46$ & $32.376,98$ & 0,06 & 0,11 \\
1991 & - & $1.694,14$ & $8.119,51$ & - & 449,69 & 0,03 & 0,28 \\
1992 & $37.323 .749,50$ & $283.517,76$ & 0,00 & - & 279,03 & 0,72 & 0,56 \\
1993 & $163.589,67$ & $148.248,75$ & 627,27 & - & $711.670,48$ & 0,49 & 0,89 \\
1994 & 32,62 & $125.774,98$ & 191,93 & $2.078,20$ & $1.922,10$ & 0,32 & 0,35 \\
1995 & 113,99 & 307,94 & 77,31 & $1.085,21$ & 256,40 & 0,07 & 0,28 \\
1996 & $86.210,82$ & 2981,79 & 59,53 & $1.179,98$ & $1.773,99$ & 0,02 & 0,12 \\
1997 & 786,66 & $9.257,93$ & 45,22 & 496,29 & $13.158,99$ & 0,20 & 0,12 \\
1998 & $5.940 .639,17$ & $15.484,48$ & 20,27 & 260,61 & 258,42 & 0,10 & 0,14 \\
1999 & 17,23 & $2.593,69$ & 61,59 & 902,07 & 249,16 & 1,10 & 1,02 \\
2000 & 33,46 & - & 67,72 & $1.245,72$ & 679,52 & 1,45 & 1,61 \\
2001 & - & - & 123,78 & $172.113,06$ & 917,25 & 0,62 & 3,55 \\
2002 & - & - & 94,08 & $2.206,12$ & $11.747,36$ & 1,75 & 1,97 \\
2003 & $14.990,61$ & - & 219,54 & - & $1.884,91$ & 2,39 & 3,22 \\
\hline Média & $4.353 .016,37$ & $65.540,16$ & $1.010,47$ & $50.203,27$ & $55.544,59$ & 0,66 & 0,79 \\
\hline TAC & 103.817 .88 & 2.191 .92 & 13.81 & 1210.71 & 21443.50 & 329.11 & 83.15 \\
\hline
\end{tabular}

Fonte: Elaborada pelo autor a partir de dados da SECEX/MDIC.

${ }^{1 /}$ Taxa Média Anual de Crescimento.

(-) Não houve importação do produto no ano considerado.

\subsection{Indicador de desempenho (DES)}

\section{Castanha de caju}

O indicador DES mostra que a castanha de caju perdeu participação na pauta de importação em todos os principais países de destino (Tabela 3). Dados do MDIC mostram que, em 1990, 34,41\% das importações americanas de castanha de caju, principal mercado para o produto brasileiro, eram originadas do Brasil, reduzindo-se para 26,62\% em 2003. 
Tabela 3 - Brasil: desempenho da castanha de caju nos principais países de destino, 1990 a 2003

\begin{tabular}{lcccc}
\hline Anos & EUA & Canadá & Países Baixos & França \\
\hline 1991 & $-0,47$ & 1,52 & $-1,89$ & 0,33 \\
1992 & 24,25 & 3,74 & $-2,44$ & 0,23 \\
1993 & 4,74 & $-0,07$ & $-3,86$ & 0,10 \\
1994 & $-15,63$ & $-0,47$ & $-7,85$ & $-0,68$ \\
1995 & 26,02 & 3,98 & $-8,04$ & $-0,50$ \\
1996 & $-18,91$ & 4,75 & $-9,75$ & $-0,82$ \\
1997 & 9,01 & 1,50 & $-8,42$ & $-0,89$ \\
1998 & $-5,04$ & 1,52 & $-9,29$ & $-2,43$ \\
1999 & $-40,89$ & $-1,35$ & $-17,10$ & $-1,37$ \\
2000 & $-24,85$ & $-2,47$ & $-17,45$ & $-1,81$ \\
2001 & $-38,16$ & $-5,69$ & $-14,05$ & $-2,63$ \\
2002 & $-46,04$ & $-6,10$ & $-12,79$ & $-1,00$ \\
2003 & $-31,47$ & $-6,68$ & $-14,68$ & $-1,61$ \\
\hline Média & -12.11 & -0.45 & -9.82 & -1.01 \\
\hline
\end{tabular}

Fonte: Elaborada pelo autor a partir de dados da FAO e do MDIC.

Um dos principais motivos para isso foi o aumento da participação de importantes países produtores e exportadores, como a Tanzânia e Indonésia, no comércio mundial desse produto. De acordo com dados da FAO, esses países, que exportaram 4,197 e 3,218 mil toneladas em 1990, passaram a exportar, respectivamente, 71,448 e 7,087 mil toneladas em 2003.

Desse modo, tem-se que esse produto apresenta $\mathrm{VCR}>1$ e $\mathrm{DES}<0$, ou seja, a castanha de caju é competitiva, porém tem perdido participação no mercado internacional, o que caracteriza uma "situação de vulnerabilidade". 
Manga

A manga ganhou participação nos Países Baixos, Reino Unido e Estados Unidos, o que indica uma "situação ótima", ou seja, VCR $>1$ e DES $>0$. Porém na França, a partir de 1994, tem-se verificado "situação de vulnerabilidade", já que o produto foi competitivo, mas sua participação no mercado decresceu (Tabela 4).

Os melhores desempenhos ocorreram nos Países Baixos e EUA, o que favoreceu, de certa forma, a concentração do produto nesses mercados. Os Estados Unidos podem ser uma referência para o potencial da manga no mercado externo, uma vez que estudos mostraram que apenas $30 \%$ dos consumidores norte-americanos já a experimentaram, de modo que o desempenho comercial do produto brasileiro naquele país ainda pode aumentar (Pimentel, 2000).

Em 1990, o Brasil exportava 4,64 mil toneladas de manga e, em 2003, passou para 133,32 mil toneladas. A maior inserção dessa fruta no mercado internacional pode ser explicada, principalmente, pela expansão da área plantada e pelo uso mais intensivo de tecnologias mais modernas de irrigação e pós-colheita.

\section{Melão}

Os resultados apresentados na Tabela 5 mostram que as exportações brasileiras de melão ganharam participação nos mercados do Reino Unido e Países Baixos, apresentando uma "situação ótima". Por outro lado, na Argentina verificou-se uma "situação de vulnerabilidade", devido à perda de mercado ao longo de praticamente todo o período. Deve-se ressaltar, entretanto, que essa retração no mercado argentino foi compensada pelos ganhos nos Países Baixos e Reino Unido. 
Tabela 4 - Brasil: desempenho da manga nos principais países de destino, 1990 a 2003

\begin{tabular}{lcccc}
\hline Anos & Países Baixos & EUA & Reino Unido & França \\
\hline 1991 & 0,58 & 0,63 & 0,12 & 0,06 \\
1992 & 0,67 & 1,22 & 0,60 & 0,38 \\
1993 & 7,14 & 6,94 & 0,97 & 0,04 \\
1994 & 8,61 & 4,80 & 0,37 & $-0,62$ \\
1995 & 9,36 & 7,38 & 0,54 & $-0,91$ \\
1996 & 12,70 & 7,37 & 4,11 & $-0,19$ \\
1997 & 6,49 & 4,94 & 1,49 & $-0,04$ \\
1998 & 10,78 & 6,93 & 2,96 & 0,98 \\
1999 & 9,62 & 7,77 & 2,65 & $-0,32$ \\
2000 & 12,91 & 9,17 & 0,88 & $-0,60$ \\
2001 & 17,98 & 15,03 & 2,45 & $-1,04$ \\
2002 & 13,30 & 18,53 & 1,83 & $-0,43$ \\
2003 & 22,95 & 21,84 & 3,85 & $-1,20$ \\
\hline Média & 10,24 & 8,66 & 1,76 & $-0,30$ \\
\hline
\end{tabular}

Fonte: Elaborada pelo autor a partir de dados da FAO e do MDIC.

Tabela 5 - Brasil: desempenho comercial do melão nos principais países de destino, 1990 a 2003

\begin{tabular}{lccc}
\hline Anos & Reino Unido & Países Baixos & Argentina \\
\hline 1991 & 2,65 & 2,62 & 0,06 \\
1992 & 3,38 & 1,92 & $-0,57$ \\
1993 & 12,90 & 5,50 & $-0,32$ \\
1994 & 8,77 & 10,15 & $-0,42$ \\
1995 & 1,30 & 0,80 & $-0,87$ \\
1996 & 6,56 & 3,10 & $-0,12$ \\
1997 & 2,44 & 3,67 & $-0,00$ \\
1998 & 6,82 & 6,42 & $-0,01$ \\
1999 & 5,41 & 8,66 & 0,07 \\
2000 & 5,77 & 10,24 & $-0,05$ \\
2001 & 10,24 & 17,09 & $-0,06$ \\
2002 & 7,90 & 17,13 & $-0,03$ \\
2003 & 15,44 & 22,21 & $-0,04$ \\
\hline Média & 6,89 & 8,42 & $-0,18$ \\
\hline
\end{tabular}

Fonte: Elaborada pelo autor a partir de dados da FAO e do MDIC. 


\section{Laranja}

A evolução do desempenho comercial da laranja pode ser visualizada na Tabela 6. Nos Emirados Árabes e em Portugal, a laranja brasileira apresenta-se em "situação de retirada", visto que não é competiva $(\mathrm{VCR}<1)$ e tem participação descendente no mercado $(\mathrm{DES}<0)$.

Nos Países Baixos e no Reino Unido, esse produto está em uma "situação de oportunidades perdidas", o que indica que, apesar de não apresentar vantagem comparativa, houve evolução média do comércio entre o Brasil e esses dois países, ao longo do período analisado.

Nos Países Baixos, o Brasil vem perdendo mercado desde 2001 e, no Reino Unido, essa perda ocorreu no início do período, com recuperação a partir de 1997, o que caracteriza uma "situação de oportunidade perdida" em quase todos os anos.

Tabela 6 - Brasil: desempenho comercial da laranja nos principais países de destino, 1990 a 2003

\begin{tabular}{lcccc}
\hline Anos & Países Baixos & Emirados Árabes & Portugal & Reino Unido \\
\hline 1991 & 3,71 & 0,45 & $-0,71$ & 0,05 \\
1992 & 2,76 & 0,04 & $-0,95$ & 0,00 \\
1993 & 7,15 & $-0,42$ & $-0,75$ & 0,00 \\
1994 & 9,15 & 0,23 & $-0,10$ & 0,00 \\
1995 & 11,51 & $-1,17$ & $-0,26$ & 0,00 \\
1996 & 5,32 & $-1,69$ & $-1,04$ & 0,89 \\
1997 & 4,92 & $-0,41$ & $-0,93$ & 1,30 \\
1998 & 1,44 & $-0,42$ & $-1,08$ & 0,44 \\
1999 & 1,58 & $-0,22$ & $-0,75$ & 1,76 \\
2000 & 0,03 & $-0,34$ & $-0,84$ & 1,64 \\
2001 & $-0,42$ & 0,02 & $-0,52$ & 2,83 \\
2002 & $-6,78$ & $-2,84$ & $-0,73$ & 0,96 \\
2003 & $-8,64$ & $-0,96$ & $-0,70$ & 1,87 \\
\hline Média & 2,44 & $-0,59$ & $-0,72$ & 0,90 \\
\hline
\end{tabular}

Fonte: Elaborada pelo autor a partir de dados da FAO e do MDIC. 


\section{Banana}

As exportações da banana brasileira apresentaram pouca evolução nos seus principais mercados de destino. No mercado Argentino, houve ganhos até 1992 e, de 1993 a 2001, verificaram-se sucessivas perdas de participação, que se recuperou apenas em 2002 e 2003. No Uruguai, o desempenho foi ainda menos favorável. De modo geral, quando se consideram os valores médios do indicador $\mathrm{DES}<0$, juntamente com o valor do indicador VCR $<1$, identifica-se uma "situação de retirada" nesses países, de modo que o Brasil não é competitivo e tem participação descendente nesses mercados desse produto (Tabela 7).

\section{Maçã}

Com base na Tabela 8, observa-se que houve aumento substancial da participação da maçã brasileira no mercado dos seus principais parceiros comerciais, principalmente nos Países Baixos e Reino Unido, onde ocorreram incrementos de, respectivamente, 11,15\% e 3,58\% entre 1990 e 2003. Nos Estados Unidos e Alemanha, embora em números mais modestos, também houve ganhos de mercado.

Quando se considera a desvantagem comparativa média desse produto e seu desempenho, ou seja, VCR $<1$ e DES $>0$, identifica-se uma "situação de oportunidades perdidas" para esse produto, razão pela qual o Brasil deve investir na conquista do mercado desses países.

\section{Uva}

A evolução do indicador de desempenho das exportações brasileiras de uva indica ganhos de participação nos principais mercados de destino (Tabela 9). Os maiores ganhos de mercado ocorreram nos Países Baixos e Reino Unido, com aumentos de, aproximadamente, 34\% e 14\%. Em relação à Alemanha, esse indicador apresentou tendência crescente a partir de 1999, com sucessivos ganhos de mercado. 
Tabela 7 - Brasil: desempenho comercial da banana nos principais mercados de destino, 1990 a 2003

\begin{tabular}{lcc}
\hline Anos & Argentina & Uruguai \\
\hline 1991 & 6,55 & $-0,25$ \\
1992 & 1,17 & $-0,19$ \\
1993 & $-4,82$ & 1,54 \\
1994 & $-12,97$ & $-0,59$ \\
1995 & $-12,64$ & $-8,25$ \\
1996 & $-12,87$ & $-11,30$ \\
1997 & $-13,22$ & $-10,95$ \\
1998 & $-10,23$ & $-7,90$ \\
1999 & $-10,79$ & $-6,50$ \\
2000 & $-13,93$ & $-7,05$ \\
2001 & $-12,59$ & $-6,87$ \\
2002 & 9,22 & $-1,34$ \\
2003 & 1,12 & $-0,23$ \\
\hline Média & -6.62 & -4.61 \\
\hline
\end{tabular}

Fonte: Elaborada pelo autor a partir de dados da FAO e do MDIC.

Tabela 8 - Brasil: desempenho comercial da maçã nos principais países de destino, 1990 a 2003

\begin{tabular}{lcccc}
\hline Anos & Países Baixos & Reino Unido & EUA & Alemanha \\
\hline 1991 & $-1,33$ & 0,53 & 0,03 & $-0,59$ \\
1992 & 3,71 & 1,91 & 0,31 & $-0,19$ \\
1993 & 5,75 & 1,24 & 3,04 & $-0,21$ \\
1994 & 9,62 & 0,44 & 2,97 & $-0,26$ \\
1995 & 3,00 & 0,55 & 0,62 & $-0,47$ \\
1996 & $-0,89$ & 0,19 & 0,27 & $-0,57$ \\
1997 & 8,31 & 0,53 & 0,08 & $-0,42$ \\
1998 & 1,71 & 1,95 & $-0,03$ & $-0,40$ \\
1999 & 15,94 & 4,61 & 0,29 & $-0,10$ \\
2000 & 11,98 & 6,17 & 0,22 & 2,69 \\
2001 & 7,46 & 2,08 & $-0,03$ & 1,01 \\
2002 & 9,47 & 3,88 & 0,09 & 2,46 \\
2003 & 11,15 & 3,58 & 0,09 & 2,79 \\
\hline Média & 6,61 & 2,13 & 0,61 & 0,44 \\
\hline
\end{tabular}

Fonte: Elaborada pelo autor a partir de dados da FAO e do MDIC. 
Tabela 9 - Brasil: indicador de desempenho comercial da uva nos principais países de destino, 1990 a 2003

\begin{tabular}{lcccc}
\hline Anos & Países Baixos & Reino Unido & Argentina & Alemanha \\
\hline 1991 & 1,95 & 1,62 & 0,29 & $-0,09$ \\
1992 & 2,21 & 0,58 & 2,02 & $-0,16$ \\
1993 & 6,24 & 1,99 & 3,26 & 0,16 \\
1994 & 3,01 & 0,56 & 1,79 & 0,52 \\
1995 & 5,78 & 0,28 & 1,08 & 0,14 \\
1996 & 3,30 & $-0,81$ & 1,60 & $-0,04$ \\
1997 & 2,01 & $-1,13$ & 1,47 & $-0,07$ \\
1998 & 2,23 & $-1,43$ & 2,13 & $-0,13$ \\
1999 & 2,70 & $-1,16$ & 3,81 & 0,09 \\
2000 & 6,39 & 0,30 & 3,53 & 0,70 \\
2001 & 11,86 & 2,28 & 3,01 & 0,87 \\
2002 & 18,54 & 9,40 & 0,25 & 0,70 \\
2003 & 34,88 & 14,20 & 0,54 & 1,04 \\
\hline Média & 7,78 & 2,05 & 1,91 & 0,29 \\
\hline
\end{tabular}

Fonte: Elaborada pelo autor a partir de dados da FAO e do MDIC.

Os países da Europa consomem grande parte das exportações brasileiras de uva, porém a participação do Brasil nesse mercado ainda é muito pequena quando comparada à da África do Sul, por exemplo. Segundo Nachreiner et. al. (2004), enquanto o país exportou cerca de 2,5 milhões de caixas de 4,5 km em 2001, a África do Sul exportou cerca de 40 milhões de caixas, com o mesmo peso, para a Europa.

Em termos médios, esse produto, assim como a maçã, apresenta uma "situação de oportunidades perdidas", ou seja, apesar de ser não competitivo, $\mathrm{VCR}<0$, o seu desempenho comercial foi positivo, DES $>0$, o que mostra uma conquista de espaço no mercado internacional. 


\section{Conclusões}

Com base na análise dos indicadores de competitividade, pode-se concluir que os "pontos fortes" da fruticultura brasileira no mercado internacional são a castanha de caju, a manga e o melão. Porém, apenas o melão e a manga estão em "situação ótima" de competitividade, ou seja, apresentam vantagens comparativas e estão aumentando sua participação nos mercados de destino, visto que a castanha de caju se apresentou vulnerável em todos os mercados de destino.

A banana e a laranja são produtos de grande importância na pauta de exportações brasileiras. No entanto, a banana está em "situação de retirada", isto é, "desvantagens comparativas" e perdas de participação nos principais mercados de destinos. Com relação à laranja observamse duas situações; nos Emirados Árabes e em Portugal, esse produto está em "situação de retirada" e nos Países Baixos e Reino Unido, em "situação de oportunidades perdidas".

Apesar de representarem "pontos fracos" para o setor, a maçã e a uva têm conseguido um bom desempenho nos mercados de destino, representando, desse modo, uma "situação de oportunidade perdida", com reais possibilidades de se tornarem, no curto prazo, mais competitivas no mercado internacional.

Em termos gerais, pode-se concluir que o grande potencial brasileiro para a produção de frutas, aliado à abertura comercial, pode estabelecer, em futuro próximo, um diferencial de competitividade a favor desse setor. Porém, deve-se considerar que os ganhos de competitividade requerem, além das vantagens comparativas, outros aspectos como melhorias na qualidade e na produtividade do setor e desenvolvimento de estratégias comerciais eficientes e adaptadas às novas condições vigentes nos mercados internacionais que superarem as práticas tradicionais. 
Tais fatores são essenciais para criar condições de transformar as vantagens naturais da fruticultura brasileira em competitivas e aumentar a participação da fruticultura brasileira no mercado externo.

\section{Referências}

AGROANALYSIS. Frutas: cresce a exportação. Agroanalysis, Rio de Janeiro, v. 25, n. 6, p. 29-30, jun., 2005.

BALASSA, B. "Trade Liberalization and "Revealed" Comparative Advantage", Manchester School of Economic and Social Studies, n. 33 , mai., 1965.

FAO. FOOD AND AGRICULTURE ORGANIZATION OF THE UNITED NATIONS. Agricultural Data. FAOSTAT. Disponível em < http://www.mdic.gov.br> Vários acessos..

HAGUENAUER, L. Competitividade: conceitos e medidas. Uma resenha da bibliografia recente com ênfase no caso brasileiro. UFRJ. Instituto de Economia Industrial. Rio de Janeiro, 1989.

HIDALGO, A. B. Especialização e competitividade do Nordeste no mercado internacional. In: Revista Econômica do Nordeste. Fortaleza, v. 29, Número especial.p.491-515, Jun. 1998.

KOSOKI, A. R.; ANDRIGUETO J. R. Ferramenta para aumentar a competitividade. Agroanalysis, Rio de Janeiro, v. 23, n. 9, p. 27-28, dez. 2003.

MDIC/SECEX . MINISTÉRIO DO DESENVOLVIMENTO INTEGRAÇÃO E COMÉRCIO EXTERIOR - Secretaria de Comércio Exterior - Disponível em: www.desenvolvimento.gov.br/indicadores/dos/ EvoluçãoCEbrasileiro.xls. Vários acessos. 
NACHREINER, M. et. al. Sistema agroindustrial do melão: Mossoró versus Juazeiro. Disponível em <http//www.cepea.esalq.usp.br/indicador/ hort/ >. Acesso em 08/02/2005.

PIMENTEL, C. R. Oportunidades e barreiras à expansão do comércio internacional para a manga. In: Revista Econômica do Nordeste, Fortaleza, v.31, n.2 p.166-176, abr./jun. 2000.

SILVA, V. da. et.al. Indicadores de competitividade internacional de produtos agrícolas e agroindustriais brasileiros, 1986- 1998. In: Revista agricultura. São Paulo, SP, p. 69-87, 2001.

\begin{abstract}
This article uses the indicator of revealed comparative advantage, the covering tax and the acting indicator to analyze the competitiveness of the Brazilian exports of fruits in the international market in the period between 1990 and 2003. The obtained results show that to chestnut-of-cashew, the mango and the melon represent the "strong points" of that section. However, among these, just the mango and the melon are in great situation of competitiveness. Other products of great importance, as the orange and the banana, are in "retreat situation", with comparative disadvantage and participation loss in the main markets of destinies. In relation to the acting, the Brazilian horticulture has been enlarging his/her space in the international market, especially in Netherlands and United Kingdom.
\end{abstract}

Key words: competitiveness, comparative advantage, Brazilian fruits. 
REVISTA DE ECONOMIA E AGRONEGÓCIO, VOL.5, $N^{o} 4$ 